\title{
An Experimental Comparison of the Effectiveness of Cool Colors as Environmental Stimulus on the Elderlies in High- rise Condominiums of Kuala Lumpur
}

\author{
Amin Ghashghaei*, Hazreena Binti Hussein, Amirhosein Ghaffarianhoseini, Ali \\ Ghaffarianhoseini \\ *Department of Architecture, Faculty of Built Environment, University of Malaya, Kuala Lumpur, \\ Malaysia
}

*amin.line@yahoo.com

Received: 14 October 2017 Final Version Received: 23 June 2017

The rapid urban spatial expansion and population growth in recent years has resulted in the development of numerous high-rise condominiums in Kuala Lumpur. Many of these buildings include general relaxation and recreational facilities for the occupants. However, the majority of these spaces are designed to cater for the basic needs of typical residents, with less attention to the expectations of the elderlies. As a result, elderlies residing in such condominiums predominantly prefer to stay in their flats, and this phenomenon can negatively impact their overall health and quality of life. While with an appropriate consideration of shared facilities this occurrence can be solved. In this study, cool colours in fifteen intensities were tested (10 minutes as the test duration for each intensity) on 64 elderly occupants in a $3 \mathrm{~m} \times 2 \mathrm{~m}$ test room based on the Quasi-experimental method to evaluate the impacts of cool colours as environmental stimulus in common indoor facilities of condominiums. The participants were the residents of two high-rise condominiums in Kuala Lumpur, and they were all above 60 years old. Their blood pressure, heart beat rate and skin temperature as dependent variables were measured by sphygmomanometer and infrared thermometer as two required instruments and analysed to evaluate their relationship with cool colours and time spent. There are three significant results: Firstly, the lightest intensity of bluegreen and green colours have decreased dependent variables with strongest relationship. Secondly, violet has negative impacts by increasing dependent variables. And thirdly, green colour, in general, has decreased dependent variables with positive impact as environmental stimulus while lightest blue-green colour affects the dependents variable faster than the other intensities. Higher rate of dependent variables associated with arousing feeling, while lower rate of dependent variables associated with calm and relaxation feeling. The study concludes that particular cool colours embrace promising potentials to be taken into consideration during the design of indoor spaces, particularly for the elderlies, by architects and interior designers.

Keywords: Elderly Residents, Cool Colours, Common Indoor Facilities, High-rise Condominiums, Environmental Stimulus

\section{INTRODUCTION}

Perverse dependence of the contemporary human on technology is constantly changing the daily lifestyle (Dociu, 2013). While this might be contributive to enhancing the quality of life regardless of its challenges, it might be unpleasant for the elderly as it might be difficult for them to adapt themselves to these changes (Blažun, et al., 2014). As a result, in many occasions, the elderlies might be 
disengaged from the communities and their surroundings, which can negatively affect their health and well-being (Gabriel, et al., 2014). This neglection can commonly lead to the isolation of the elderlies (Iliffe and Manthorpe 2014). Recent studies demonstrate that three challenges of "neglect, isolation and fear" are always connected to each other in the context of the well-being of elderlies (Kurt and Jellinger, 2014). These challenges can get more intensified once being intertwined with the feeling of boredom or idleness (HelpAge India, 2011).

Kuala Lumpur as the most populous city in Malaysia is no exception from this phenomenon. According to the Kuala Lumpur City Hall in 2015, 9.8\% of the overall 1.67 million population of the city are elderlies. They are struggling with some physical and psychological issues as a result of disengaging from the communities and their surroundings, which can affect their quality of life and wellbeing (Ainoriza et al., 2016, Lim et al., 2014). Following a personal observation conducted by the researcher as the preliminary study with a focus on 300 elderlies in Kuala Lumpur high-rise condominiums, it has been proven that the elderlies over 60 years old spend the majority of their time at home compared to the other age groups (Ogundele, 2010). The study also reported that approximately 150 to 280 elderly occupants depending on the buildings population live in such condominiums in Kuala Lumpur. In general, most condominiums in Kuala Lumpur have standard facilities for relaxation and entertainment of residents. Nevertheless, the majority of these shared amenities are designed with considerably less attention to the expectation of elderlies (Ogundele, 2010). Referring to the rapid population growth and numerous constructions of high-rise condominiums in Kuala Lumpur (Stella, 2015), the aim of this study is to investigate the quality of typical indoor facilities in these buildings from the elderlies' preferences. To achieve this aim, the objectives are to examine the impacts of cool colors: to explore the spectrum of cool colors; and to test their effectiveness as environmental stimulus on elderlies to get the most relaxation level within standard indoor facilities of high-rise condominiums.

\subsection{ELDERLY VISUAL ABILITY}

Ageing changes human body physiologically and accordingly (Lord, 2006; Sturnieks et al., 2008), affects the optical system. With ageing process, our eyes struggle with several issues such as: gradual reduction in accommodation; reduction in pupil diameter; yellowing pigmentation of the lens; and boost absorption and scatter of light in the ocular media (Shariful et al., 2012). Suffering with one of these issues effects visual performance for elderlies. They will face with a number of visual difficulties such as: poor night vision, lack of colour perception, reduce visual acuity, reducing the contrast sensitivity, the loss of visual field and the continuity of light and dark interference (Lord, 2006; Veiel et al., 2006; Sturnieks et al., 2008). Elderlies are not sensitive on detecting temporary objects. They need to spend more time on detection (Blake et al., 2008) and this issue effects the colour detection on them as well (Ho et al., 2001). Therefore, the visual effect of colour on elderlies is different to the other age group, which needs a comprehensive investigation accordingly (Dijkstra et al., 2006).

Within the years a few studies investigates the visual impact of colours on elderlies. Birren (1961) identified that colour affects elderlies body physiologically and psychologically, where colour influence mood and personality as well as close relationship with emotion. Tate and Allen (1985) conducted a study about colour impact on elderlies. They realized that elderlies do not prefer dark colours and they are more interested on light colours instead. They also found that light green is the most preferred colour. There were no any significant different between men and women. Dittmar (2001) mentioned that ageing increases the popularity of blue colour on elderlies, while 
paradoxically the dark colours popularity decrease gradually.

\subsection{COOL COLOURS AGAINST WARM COLOURS}

Colour gives life to our environment through the fibers, finishes, surfaces, and sculptures in architecture and enhances the impacts of architectural expressions (Naseri and Tamizi 2011). Dijkstra et al. (2006) and Ulrich et al. (2004) showed that the psychological effect of an environment could release stress and increase the feel of relaxation. Previous researchers classified the comparison of colour emotions. Warm colours associated with aroused feeling and cool colours associated with calm and relaxation feeling (Kaya \& Epps, 2004). Dijkstra et al. (2006) mentioned the primary environmental stimulus is the colour of the walls in an environment, which will change the feeling of the place to get an appropriate result in human health. They added, colours in an indoor environment could be a beneficial effect on patients as the first healing factor in a healthcare system. They also identified that warm colours including red, yellow and orange in an indoor place will arouse human feeling while cool colours including blue and green associates with relax and calm feeling. Dijkstra et al. (2006)_ further stated that many researchers have investigated the role of colours and the possibilities of their optimal use for the enhancement of the quality of the built environments. Dijkstra et al. (2006) analyzed the impact of cool and warm colours through survey studies and proved that warm colours in an indoor environment arouse human feeling while cool colours like blue and green result in the sense of relaxation and calmness. They tested the wall colours (white vs. green) as a stimulus based on 89 participants who were students with an average age of 20.4 years. The result showed that the green walls have a significant impact on the reduction of stress on low-screeners $(\mathrm{p}=0.05)$. Ross et al. (2013) evaluated the visual impact of colours through a Quasi-experimental study and realized that warm coloured lights affect the human nerves negatively. She tested 117 participants, 28 men and 89 women who were divided into two locations randomly. The average age of the participants was 43 , and three types of coloured light were projected to an interior environment to evaluate the psychological impact of coloured light as environmental stimulus. Elliot and Maier (2014) analyzed colour aesthetics to assess the relation between color and human psychological behavior. They similarly found that each color has a particular impact on the elderly feeling.

\subsection{COLOUR AND CULTURE}

Jiang and $\mathrm{Lu}$ (2014) stated that personal experience and cultural background strongly affect the impact of colour on human psychological perception. They added that the religious beliefs could influence the effect of colours. For instance, white colour represents death in China and India while black is a colour of death in many other countries (Barbara, 2011). In many European countries and the United States, green is sometimes the sign of devil, sickness and death (Heller, 2009). Blue is a symbol of immortality in China and in contrary; it is a symbol of sadness in most of the European countries (Barbara, 2011). Regardless of the historical and cultural impacts of colours on humans, each colour with a different rate of intensity encompasses basic emotional brunt on the human body through the visual sense (Elliot and Maier, 2014; Shariful et al., 2012).

\subsection{COLOUR AND INDOOR ENVIRONMENT}

Colour affects how people interpret the environment. Of the most effective stimulus of an indoor space are the interior walls. They affect the way people feel and behave (Dijkstra et al., 2006). Willard et al. (2008) mentioned that colour is the most effective architectural and environmental stimulus in an indoor space impacting the human body psychologically. Colours impact human body psychologically 
through, blood pressure, heart rate, respiration, digestion, body temperature, and brain activity (Ross et al., 2013). Babin et al. (2003) realized that the colour of the walls plays the main role in users' judgment about space. He tested the impact of wall colour as an environmental stimulus on consumers' behaviour in a different type of stores. The study realized that the stores with blue interior are more associated with desirable appraisement while the store with orange interior are more associated with ill effects on consumers.

The opposite effect of warm and cool colours in the interior environments has been proven over the years (See Table 1). Hidayetoglu et al. (2011) tested 102 participants to find the bright/blurry, attractive/unattractive, navigable/unnavigable and inviting/repellent of an indoor corridor (way-finding). The result demonstrated that warm colours were more appealing colours for participants, if, the cool colours were more attractive for them. They also realized that the females preferred brighter colours range for indoor corridors. Ross et al. (2013) tested 117 participants, 28 men and 89 women who were divided into two locations randomly. Their average was 43 , and three types of coloured light were projected into an interior environment to evaluate the psychological impact of glowing light as an environmental stimulus with the similar research approached used by Ulrich (1984) and Wong (2001). Blood pressure, heart beat rate, and skin temperature were measured while the Profile of Mood States (POMS) test was used to get the effect of colour on the sensation and mood of respondents. The study revealed that coloured light could be utilized as a chromotherapy approach (A quasi-experimental method as a correlational study considered in analyzing the data). The result shows that lighter colours have the most negative correlation with all variables.

Table 1: Key findings of the core studies with focus on the impacts of colours

\begin{tabular}{|c|c|c|}
\hline Reference & Area of study & Key findings \\
\hline Bailey (2006) & $\begin{array}{l}\text { Warm colours, cool } \\
\text { colours }\end{array}$ & $\begin{array}{l}\text { Warmer colours appearing nearer in } \\
\text { depth to viewers than cooler colours }\end{array}$ \\
\hline $\begin{array}{l}\text { Cooper et } \\
\text { al.(1991) }\end{array}$ & & $\begin{array}{l}\text { The staffs in the warm environment } \\
\text { were less cheerful than the other } \\
\text { office }\end{array}$ \\
\hline $\begin{array}{l}\text { Dijkstra( } \\
2006)\end{array}$ & & $\begin{array}{l}\text { - Warm colours like red, yellow, } \\
\text { orange in an indoor place will } \\
\text { arouse human feeling, while cool } \\
\text { colours like blue and green will } \\
\text { associate with relax and calm } \\
\text { feeling } \\
\text { - Wall colour cause people to verdict } \\
\text { about that place. It affects the way } \\
\text { people feel and behave }\end{array}$ \\
\hline $\begin{array}{l}\text { Hidayetoglu et } \\
\text { al.,(2011) }\end{array}$ & & $\begin{array}{l}\text { - Warm colours were more attractive } \\
\text { colours for participants, in the event } \\
\text { that, the cool colours were more } \\
\text { positive }\end{array}$ \\
\hline
\end{tabular}




\begin{tabular}{|c|c|c|}
\hline \multirow[b]{2}{*}{$\begin{array}{l}\text { Huchendorf } \\
(2007)\end{array}$} & & $\begin{array}{l}\text { - They also realized that the females } \\
\text { preferred brighter colours range for } \\
\text { indoor corridors }\end{array}$ \\
\hline & & $\begin{array}{l}\text { Warm colours could help people to } \\
\text { remember }\end{array}$ \\
\hline $\begin{array}{l}\text { Elliot and } \\
\text { Maier (2014) }\end{array}$ & \multirow[t]{10}{*}{$\begin{array}{l}\text { Colour emotions, } \\
\text { mood and behavior }\end{array}$} & $\begin{array}{l}\text { Each colour has a particular } \\
\text { consequence on human feeling }\end{array}$ \\
\hline $\begin{array}{l}\text { Kaya and } \\
\text { Epps (2004) }\end{array}$ & & $\begin{array}{l}\text { - Warm colours associate with } \\
\text { aroused feeling and cool colours } \\
\text { associate with calm and relaxation } \\
\text { feeling }\end{array}$ \\
\hline \multirow{4}{*}{$\begin{array}{l}\text { Wexner } \\
(1954)\end{array}$} & & $\begin{array}{l}\text { - Most positive feeling by green } \\
\text { colour }\end{array}$ \\
\hline & & $\begin{array}{l}\text { - Warm colours associate with } \\
\text { aroused feeling and cool colours } \\
\text { associate with relaxation }\end{array}$ \\
\hline & & $\begin{array}{l}\text { - Green colour is more related to the } \\
\text { relaxation, comfortable and calm }\end{array}$ \\
\hline & & $\begin{array}{l}\text { - Orange colour has the effect of } \\
\text { upset, excitement and distress on } \\
\text { human }\end{array}$ \\
\hline \multirow{4}{*}{$\begin{array}{l}\text { Jacob and } \\
\text { Suess (1975) } \\
\text { Mehrabian, } \\
(199) \\
\text { Knez (2001) }\end{array}$} & & $\begin{array}{l}\text { Red and yellow colour gets more } \\
\text { discomposure feeling }\end{array}$ \\
\hline & & $\begin{array}{l}\text { Cool colours associate with calm } \\
\text { and relaxation }\end{array}$ \\
\hline & & Colour effects mood \\
\hline & & Colour effects behavior \\
\hline \multirow{3}{*}{$\begin{array}{l}\text { Babin et. al. } \\
\text { (2003) } \\
\text { Dijkstra } \\
(2006) \\
\text { Willard et al. } \\
(2008)\end{array}$} & \multirow[t]{3}{*}{$\begin{array}{l}\text { Wall colour in an } \\
\text { indoor environment }\end{array}$} & $\begin{array}{l}\text { Colour on walls play the main role } \\
\text { in people judgment in a place }\end{array}$ \\
\hline & & $\begin{array}{l}\text { The green room, experienced less } \\
\text { stress than the white room }\end{array}$ \\
\hline & & $\begin{array}{l}\text { Colour is the most effective } \\
\text { architectural environmental stimulus } \\
\text { in an indoor place, }\end{array}$ \\
\hline \multirow{2}{*}{$\begin{array}{l}\text { Tsunetsugu et } \\
\text { al. (2013) } \\
\text { Ulrich (1984) }\end{array}$} & \multirow[t]{2}{*}{ Greenery vs urban } & $\begin{array}{l}\text { Forest views had more positive } \\
\text { score on human feeling }\end{array}$ \\
\hline & & $\begin{array}{l}\text { Patients who were looked to the } \\
\text { greenery were more influenced } \\
\text { positively }\end{array}$ \\
\hline
\end{tabular}

40 Journal of Design and Built Environment Vol. 17 (1), June 2017 Amin G. et. al 


\begin{tabular}{|l|l|l|l|}
\hline Myers (2006) & & $\begin{array}{l}\text { Elderly, colour and } \\
\text { health }\end{array}$ & $\begin{array}{l}\text { Red and yellow can, treat Alzheimer } \\
\text { disease on elderlies }\end{array}$ \\
\cline { 3 - 3 } $\begin{array}{l}\text { Shariful et al. } \\
(2012)\end{array}$ & & $\begin{array}{l}\text { Increasing physical health of elderly } \\
\text { residents by relaxation and spiritual } \\
\text { healing }\end{array}$ \\
\cline { 3 - 4 } Wong (2001) & & $\begin{array}{l}\text { More beneficial effect on the } \\
\text { physical health by viewing the } \\
\text { garden }\end{array}$ \\
\hline $\begin{array}{l}\text { Jiang and Lu } \\
(2014)\end{array}$ & & $\begin{array}{l}\text { Colour vs. culture } \\
\text { and historical } \\
\text { Tofle et al. } \\
(2004)\end{array}$ & $\begin{array}{l}\text { Personal history and cultural } \\
\text { background strongly affect colour } \\
\text { impact }\end{array}$ \\
\cline { 3 - 4 } & & $\begin{array}{l}\text { Cultural and historical background } \\
\text { influence the impact of colour }\end{array}$ \\
\hline
\end{tabular}

Each cool colour impact elderlies differently and any intensities of each colour has different impact as well. While, Visual impact of colour as environmental stimulus on any intensity can significantly measure through blood pressure, heart beat rate and skin temperature (Ross et al., 2013). Consequently, Cool colours in deferent intensities have not been tested; especially on elderly participants as environmental stimulus and it is a gap in previous studies.

\section{RESEARCH METHOD}

This study investigates the effectiveness of cool colours as an environmental stimulus on the elderly occupants residing in highrise condominiums in Kuala Lumpur, as the reason of warm colours associates with aroused feeling and cool colours associates with calm and relaxation feeling (Kaya and Epps, 2004). Literature presented that the visual environmental stimulus affects human body through 4 main parameters (Tsunetsugu et al., 2013). This includes maximum blood pressure (systolic), minimum blood pressure (diastolic), heart beat rate (beats/min) and skin temperature $\left(\mathrm{C}^{\circ}\right)$ as similarly considered by previous studies (Willard et al., 2008; Thompson,
2011; Tsunetsugu et al., 2013; Ross et al., 2013; Noonan and Nguyen, 2013). Following a similar approach, this study utilizes the Quasi-experimental method as a correlational study to measure the impact of cool colours including green, blue-green, blue, blue-violet and violet with three levels of intensities, namely light, medium and dark. To correctly run the experiments, preliminary consultations were carried out with two psychologists to increase the researcher's awareness and capabilities for the experimental process.

\subsection{LOCATION AND PARTICIPANTS}

There are approximately 957 high-rise condominiums in Kuala Lumpur and among these buildings, $689 \quad(71.99 \%)$ are categorized as the middle-income group (Ismail, 2014). Approximately all of the middle-income condominiums have standard facilities with different levels of design quality. Meanwhile, in about 150 to 280 elderly occupants reside in each condo depending on home population based on personal observation in the preliminary site study. Higher elderly residents, more residential floors, units and facilities as well as new constructed buildings were considered as criteria to choose the case studies. To experiment our hypothesis in this

41 Journal of Design and Built Environment Vol. 17 (1), June 2017 Amin G. et. al 
research, the D'Alamanda, and Connaught Avenue condominiums were selected (See Figure 1). Table 2 demonstrates the collected information about these two locations.

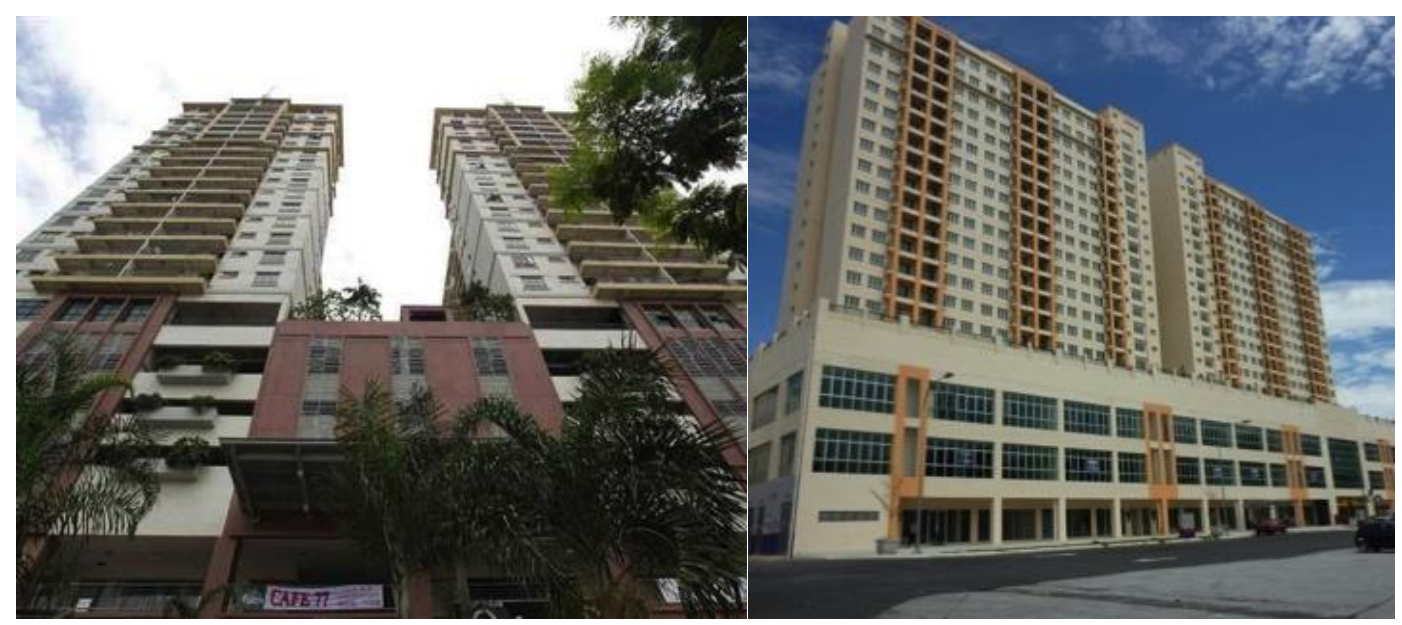

Figure 1. D'Alamanda (left) and Connaught Avenue (right)

\begin{tabular}{|lcc|}
\hline & D'Alamanda & Connaught Avenue \\
\hline Number of floors & 20 & 20 \\
Number of Blocks & 5 & 2 \\
Residential floors & 7 th to 20 th & 3rd to 20th \\
Number of units per floor & 12 & 12 \\
Residents in each block & 672 & 944 \\
Total population & 3360 & 1888 \\
Elderly population & 280 & 185 \\
\hline
\end{tabular}

Table 2: Statistics of the selected condominiums 
Cultural and the historical background play a significant role in the visual impact (Deanne, 2000). In general, Kuala Lumpur is the home of three races: Malay, Chinese and Indian. Approximately, $67.9 \%$ of the Malaysian population is dominated by the Malay race (Jabatan Perangkaan Malaysia, 2013) with the elderly population of $9.8 \%$. This study is limited to the Malay participants only. All participants were selected from the elderlies at the age of 60 and above, which is following the approximate retirement age of Malaysian employees (Randstad Workmonitor, 2015).

All participants were primarily screened to be in good health and all were trained and prepared for the test accordingly.

\subsection{SAMPLE SIZE AND INSTRUMENTS}

G-power was used for sample size calculation (Faul et al., 2007; 2009). Total sample size was calculated, and the results of power analysis indicated that the minimum required sample size was 64 respondents. The power of the test was considered 0.8 (as a common value for power in the research in human science) and $\alpha=0.05$ with medium effect size. Table 3 represents the results of power analysis using G-Power version 3.1.9.2. Likewise, Figure 2 shows the result of T-tests for sample size extracted from G-power software.

Table 3 Results of power analysis using G-Power version 3.1.9.2

\begin{tabular}{|l|c|}
\hline \multicolumn{2}{|c|}{ Tests - Correlation: Point biserial model } \\
\hline \multicolumn{2}{|c|}{ Analysis: Compute required sample size } \\
\hline Input: Tail(s) & One \\
\hline Effect size $|\rho|$ & 0.3 \\
\hline$\alpha$ err prob & 0.05 \\
\hline Power $(1-\beta$ err prob) & 0.8 \\
\hline Output: Noncentrality parameter $\delta$ & 2.5158836 \\
\hline Critical t & 1.6698042 \\
\hline Df & 62 \\
\hline Total sample size & 64 \\
\hline Actual power & 0.8005036 \\
\hline
\end{tabular}

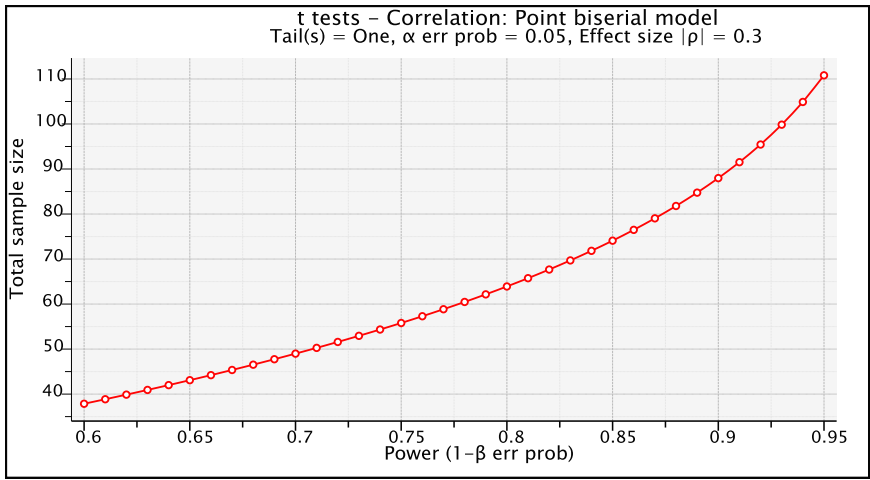

43 Journal of Design and Built Environment Vol. 17 (1), June 2017 Amin G. et. al 
Figure 2. Result of T-tests for sample size extracted from G power software

A sphygmomanometer for measuring blood pressure and heart beat rate and a thermometer for recording skin temperature was required in conducting this study. According to the consultations with the psychiatrists, it was compulsory to run the experiments without any physical contact with the participants. As a result, an 'iHealth' device (Model BP5) was chosen for measuring the blood pressure and heart beat rate with pressure accuracy of $\pm 3 \mathrm{~mm}$
$\mathrm{Hg}$ and pulse rate accuracy of $\pm 5 \%$ (iHealthLab, 2016). Furthermore, an 'Infrared Thermometer' device (Model IT903) was chosen for measuring the skin temperature with \pm 0.5 degree Celsius accuracy (Globalsources, 2016) (See Figure 3 ). As running the experiments and the operations of instruments required necessary skills, a cardiothoracic nurse provided sufficient training to increase the examiner's awareness and expertise for such operation.

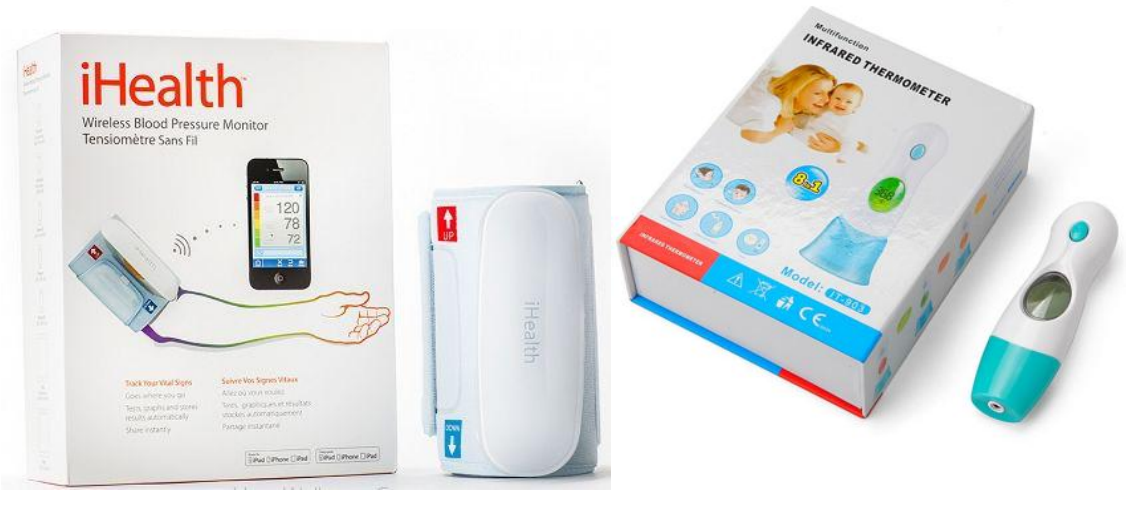

Figure 3. iHealth, model BP5 (left), Infrared Thermometer, model IT-903 (right)

\subsection{PROTOCOL STUDY}

The other environmental elements such as light, furniture and shadows affect the colour impact in an indoor environment as well. Therefore, in order to get the pure colour impact on participants, projecting the colours individually considered according to the psychiatrists' advice. A $3000 \mathrm{~mm}$ (L) *
$2000 \mathrm{~mm} * 3000 \mathrm{~mm}(\mathrm{H})$ room located in the selected condominiums was selected as the test room during the experiment. 3 of the four interior walls were completely covered with a black fabric with an acceptable thickness and a white fabric covered the interior front wall as the screen for the colour exposure. The black fabric also covered the entrance door located behind the 
participants to avoid any reflections.

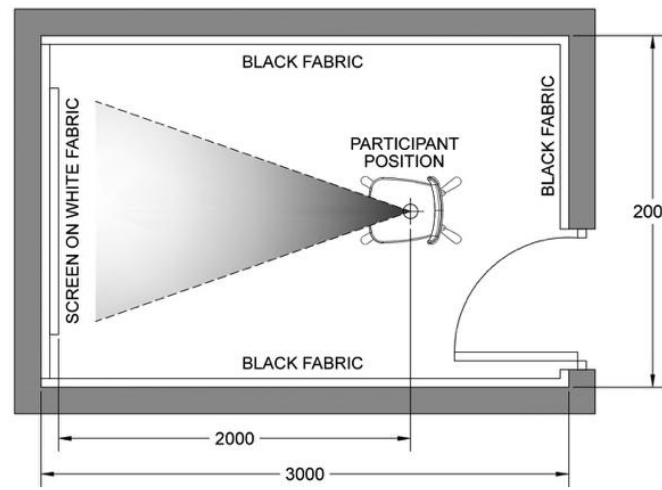

Figure 4. Layout of the experimental platform

The respondents were located $2000 \mathrm{~mm}$ away from the screen, in the middle of the room. Figure 4 shows the plan layout of the test room. Figure 5 demonstrates the preparations in the test room before the initiation of the data collection.

All of the participants sat in a position to clearly see the screen during the projection of the colours. The duration of each test was 10 minutes. During the entire experiments, the room temperature was set to $23^{\circ} \mathrm{C}$ following the satisfactory healing standard for elderly indoor temperature (David \& Watkins, 2011). The study concentrated on 15 cool colours, which were categorized into five main classifications



Figure 5. Preparations at the test room before data collection

(See Figure 6). Each primary colour was divided into three different intensities (high, medium, low). Since the projection done through the computer, the colour mode, which was considered for this study, was RGB (Red, Green, and Blue), refers to a universal system for displaying the colours on a computer device. Red, green, and blue can be combined in various proportions to obtain any colour in the visible spectrum. Levels of R, G, and B can provide each range from 0 to 100 percent of full intensity (Sharma, 2004). The value of each parameter was identified in Adobe Photoshop software version CS6. Table 4 shows the RGB values for all color intensities. 


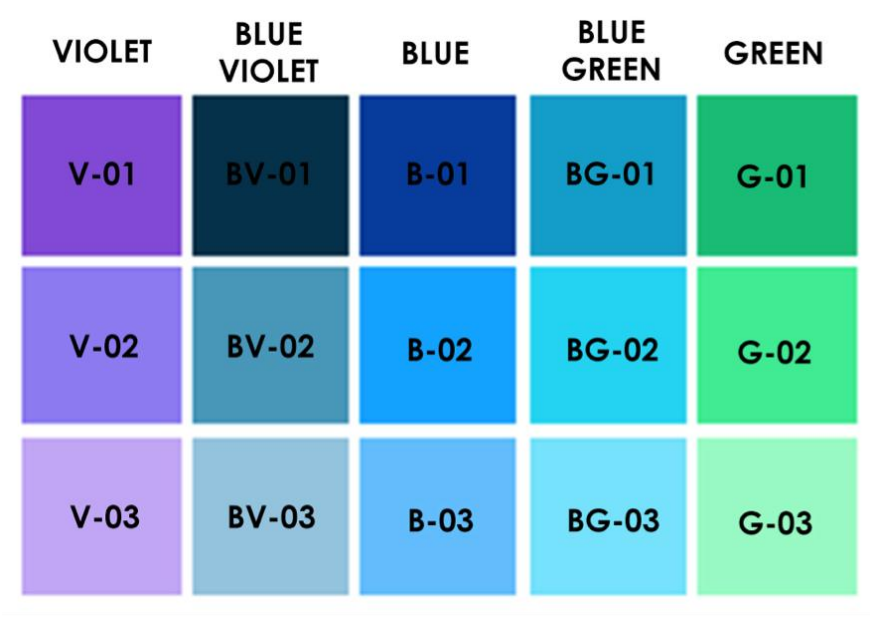

Figure 6. Demonstration and Classification of the fifteen cool colours in 5 groups

Table 4. RGB values with reference to the colour groups

\begin{tabular}{|c|ccccccccccccccc|}
\hline & G1 & G2 & G3 & BG1 & BG2 & BG3 & B1 & B2 & B3 & BV1 & BV2 & BV3 & V1 & V2 & V3 \\
\cline { 2 - 36 } & 1 & 71 & 166 & 1 & 29 & 132 & 1 & 0 & 115 & 0 & 87 & 164 & 149 & 158 & 206 \\
G & 196 & 235 & 249 & 173 & 219 & 231 & 82 & 179 & 203 & 66 & 168 & 206 & 101 & 146 & 184 \\
B & 136 & 164 & 207 & 211 & 245 & 252 & 173 & 254 & 253 & 92 & 198 & 228 & 221 & 244 & 248 \\
\hline
\end{tabular}

\subsection{DATA COLLECTION AND ANALYSIS}

According to the calculated sample size, the experiments were carried out on the participants to obtain a total of 64 acceptable test results. According to the psychiatrists' advice, every exposure from one colour intensity to another required a 10-minute resting time for each participant. During the resting time, the participants are advised to walk out from the testing room into another room with a minimal interior design where they can enjoy a cup of tea while having a conversation with others. Each participant was tested three times: one color spectrum with three ranges of intensity. Figure 7 presents an example of the data collection process for a male respondent from Connaught Avenue condo.

46 Journal of Design and Built Environment Vol. 17 (1), June 2017 Amin G. et. al 


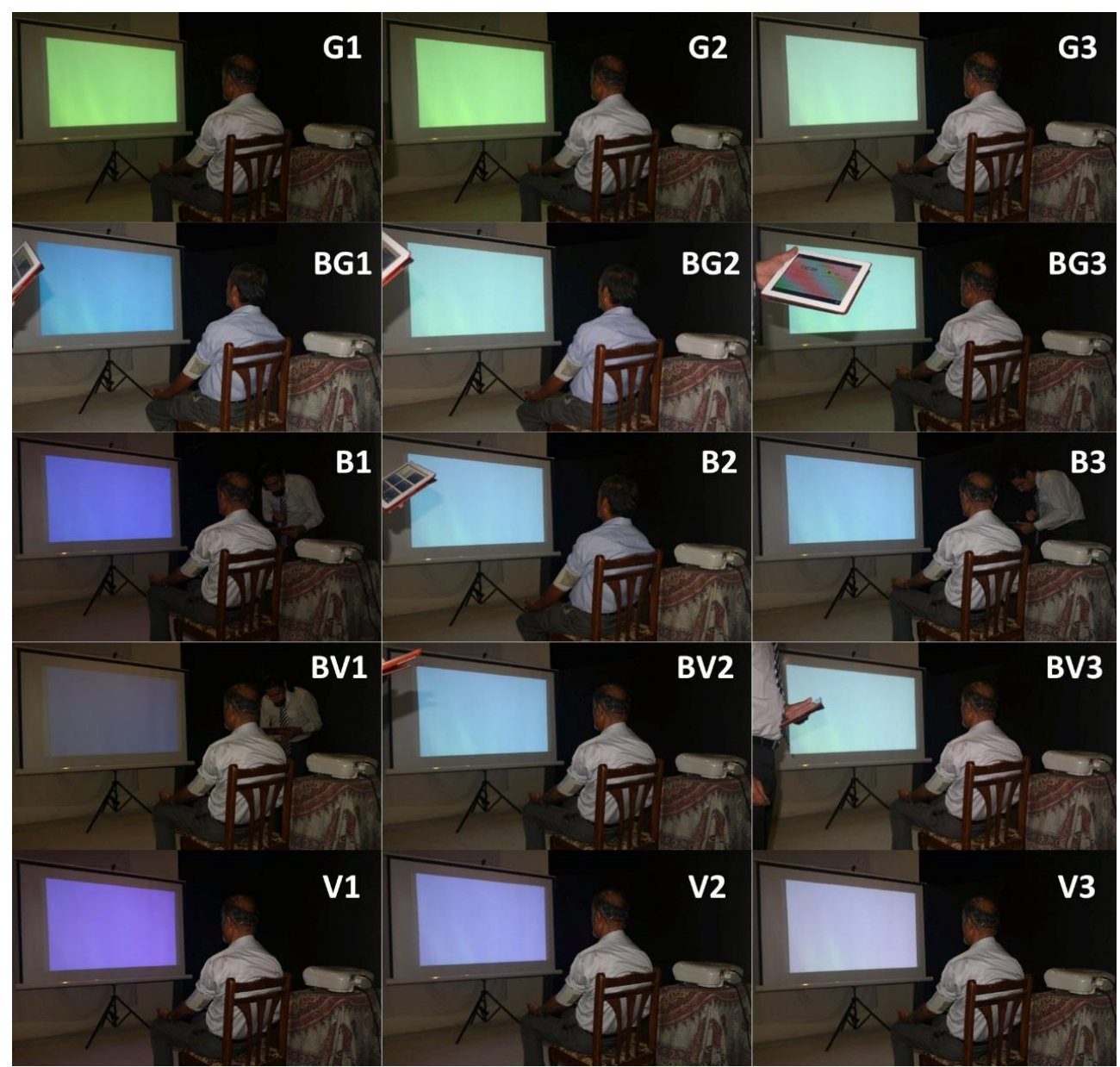

Figure 7. Sample of the data collection phase: A male participant from Connaught Avenue condo

The data entry was done in IMB SPSS software, version 22 under Windows 8 operating system. The statistical analysis involves two phases: Firstly, descriptive and secondly, Bivariate Statistics. Three steps of analysis were applied including Pearson Correlation, Means and ANOVA test.

\section{RESULTS AND ANALYSIS}

To ensure the reasonable description of the variables, all the variables objected to the normality test, using Skewness and Kurtosis (Bachman, 2004) and Kolmogorov-Smirnov, Shapiro-Wilk (Ruppert, 2004; Rovai et al., 2013). As shown in Table 5, the low value of skewness and kurtosis confirmed that systolic blood pressure, diastolic blood pressure, heart beat rate and skin temperature are statistically average considering that the acceptable range should be between " $-2 \sim+2$ " (Bachman, 2004). The normality of the variables was proved in Kolmogorov- Smirnov and Shapiro-Wilk

47 Journal of Design and Built Environment Vol. 17 (1), June 2017 Amin G. et. al 
test as well (Table 5). Furthermore, Q-Q plot distribution of the variables of this study. and box plot confirmed the standard

Table 5. Result of Kolmogorov - Smirnov and skewness - kurtosis tests

\begin{tabular}{lcccccccc} 
& \multicolumn{7}{c}{ Kolmogorov- Smirnov } & \multicolumn{3}{c}{ Shapiro-Wilk } & & \\
\cline { 2 - 7 } & Statistic & df & Sig. & Statistic & df & Sig. & Skewness & Kurtosis \\
\hline $\begin{array}{l}\text { Blood } \\
\text { pressure } \\
\text { (sys) }\end{array}$ & 0.084 & 165 & 0.006 & 0.969 & 165 & 0.001 & 0.063 & -1.154 \\
$\begin{array}{l}\text { Blood } \\
\text { pressure }\end{array}$ & 0.045 & 165 & $0.200^{*}$ & 0.99 & 165 & 0.304 & 0.174 & -0.526 \\
$\begin{array}{l}\text { (dia) } \\
\begin{array}{l}\text { Heart beat } \\
\text { rate }\end{array}\end{array}$ & 0.062 & 165 & $0.200^{*}$ & 0.983 & 165 & 0.044 & 0.867 & 1.238 \\
$\begin{array}{l}\text { Skin } \\
\text { temperature }\end{array}$ & 0.093 & 165 & 0.001 & 0.958 & 165 & 0 & -0.257 & 0.412 \\
\hline
\end{tabular}

*. This is a lower bound of the true significance.

a. Lilliefors Significance Correction

\subsection{CORRELATION TEST OF RESEARCH VARIABLES \\ 2.5.1 AGE AND DEPENDENT VARIABLES}

In the first phase of the correlation tests, the relationship between age and the dependent variables was examined. The analysis intended to demonstrate the effect of age on each dependent variable and showed that the

correlation is significant at 0.01 levels. It confirmed that through the increase of age of the elderly occupants, the maximum blood pressure (systolic), minimum blood pressure (diastolic) and heart beat rate (beats/min.) moderately increased while the skin temperature $\left(\mathrm{C}^{\circ}\right)$ weakly increased. In particular, maximum blood pressure (systolic) increased more significantly compared to the other dependent variables (See Table 6).

Table 6. Result of Pearson Correlation test between age and dependent variables

\begin{tabular}{clcccc}
\hline & & $\begin{array}{c}\text { Blood } \\
\text { pressure } \\
\text { (systolic) }\end{array}$ & $\begin{array}{c}\text { Blood } \\
\text { pressure } \\
\text { (diastolic) }\end{array}$ & $\begin{array}{c}\text { Heart beat } \\
\text { rate }\end{array}$ & $\begin{array}{c}\text { Skin } \\
\text { temperature }\end{array}$ \\
\hline \multirow{2}{*}{ AGE } & $r$ & $0.478^{* *}$ & $0.449^{* *}$ & $0.431^{* *}$ & $0.211^{* *}$ \\
& $p$-value & $<0.001$ & $<0.001$ & $<0.001$ & $<0.001$ \\
\hline
\end{tabular}

**. Correlation is significant at the 0.01 level (2-tailed) 


\subsubsection{MAIN COOL COLOURS AND DEPENDENT VARIABLES}

In this phase, the study explored the relationships between time and the dependent variables for each particular colour. The study targeted to identify which main colors, regardless of the intensities, embrace the most impact on the elderly occupants (See Table 7).

Table 7. Pearson Correlation test between time spending and research dependent variables for each main colour

\begin{tabular}{clcccc}
\hline Colors & & $\begin{array}{c}\text { Blood } \\
\text { pressure } \\
\text { (systolic) }\end{array}$ & $\begin{array}{c}\text { Blood } \\
\text { pressure } \\
\text { (diastolic) }\end{array}$ & $\begin{array}{c}\text { Heart beat } \\
\text { rate }\end{array}$ & $\begin{array}{c}\text { Skin } \\
\text { temperature }\end{array}$ \\
\hline G & $r$ & $-.719 * *$ & $-.760^{* *}$ & $-.669^{* *}$ & $-.435^{*}$ \\
& $p-$ & $<0.001$ & $<0.001$ & $<0.001$ & 0.012 \\
\hline BG & $r$ & $-.552^{* *}$ & $-.488^{* *}$ & $-.546^{* *}$ & $-.522^{* *}$ \\
& $p-$ & 0.001 & 0.004 & 0.001 & 0.002 \\
\hline B & $r$ & -0.2 & -0.192 & -0.123 & -0.107 \\
& $p-$ & 0.265 & 0.284 & 0.495 & 0.554 \\
\hline BV & $r$ & -0.185 & -0.219 & -0.226 & -0.203 \\
& $p-$ & 0.303 & 0.221 & 0.207 & 0.257 \\
\hline $\mathrm{V}$ & $r$ & $.645^{* *}$ & $.684^{* *}$ & $.822^{* *}$ & $.711^{* *}$
\end{tabular}

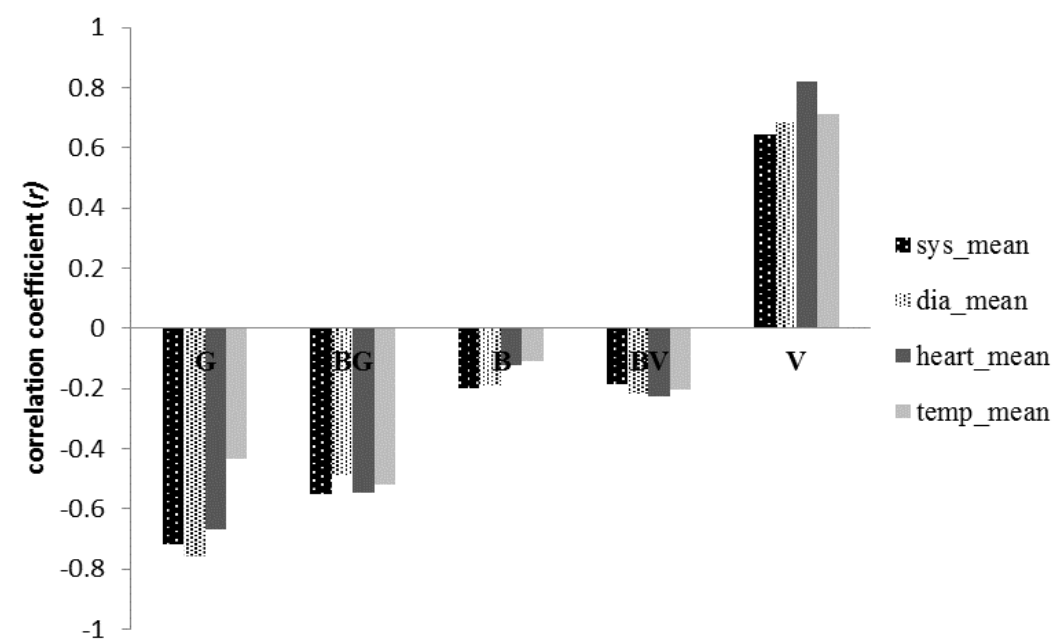

\begin{tabular}{cccc}
$p$-value $<0.001<0.001$ & $<0.001<0.001$ \\
\hline$*$ Correlation is significant at the 0.01 level (2-tailed). & \\
$*$ Correlation is significant at the 0.05 level (2-tailed).
\end{tabular}

Figure 8. Correlation coefficient ( $\mathrm{r}$ ) of each dependent variable and the main colour spectrums

49 Journal of Design and Built Environment Vol. 17 (1), June 2017 Amin G. et. al 
Table 7 shows the most positive impact on participants belonged to green $(\mathrm{G})$ colour while blue (B) colour resulted in relatively less impact. It is evident that green $(\mathrm{G})$ color has the strongest relationship with maximum blood pressure $(\mathrm{r}=-0.719)$, minimum blood pressure $(\mathrm{r}=-0.760)$, heart beat rate $(\mathrm{r}=$ $0.669)$ and skin temperature $(r=-0.435)$ with a negative direction. Figure 8 shows that green color $(\mathrm{G})$, followed by blue-green (BG), blue violet (BV) and blue (B), resulted in the most significant impacts on the reduction of dependent variables as a positive evidence of elderly occupants. On the other hand, violet embraced the most significant impact on increasing the dependent variables as the evidence of negative impact on participants.

\subsubsection{CORRELATIONS OF COLOR INTENSITIES}

ALL

In the second phase, the study intended to measure separately the linear correlations between all cool colours based on their three levels of intensity (resulting in 15 colors) and the dependent variables to identify the eventual impact of each cool colour. Table 8 summarizes the finding of the Pearson correlation test for all fifteen intensities of cool colours. Likewise, Figure 9 shows the average of the dependent variables trend line for each colour on time spending. Meanwhile, Table 9 shows the correlation coefficient $(r)$ between all colors and each particular dependent variable, sorted from lower to a higher value.

Table 8. Summarized results of the Pearson correlation test for all fifteen intensities of cool colour

\begin{tabular}{|c|c|c|c|c|c|}
\hline Color & & $\begin{array}{c}\text { Blood } \\
\text { pressure } \\
\text { (systolic) }\end{array}$ & $\begin{array}{c}\text { Blood } \\
\text { pressure } \\
\text { (diastolic) }\end{array}$ & $\begin{array}{l}\text { Heart beat } \\
\text { rate }\end{array}$ & $\begin{array}{c}\text { Skin } \\
\text { temperature }\end{array}$ \\
\hline \multirow[t]{2}{*}{ G1 } & $r$ & $-.974 * *$ & $-.971 * *$ & $-.944 * *$ & $-.915 * *$ \\
\hline & $\begin{array}{l}p \\
\text { value }\end{array}$ & $<0.001$ & $<0.001$ & $<0.001$ & $<0.001$ \\
\hline \multirow[t]{2}{*}{ G2 } & $r$ & $-.969 * *$ & $-.942 * *$ & $-.986 * *$ & $-.961 * *$ \\
\hline & $\begin{array}{l}p \\
\text { value }\end{array}$ & $<0.001$ & $<0.001$ & $<0.001$ & $<0.001$ \\
\hline \multirow[t]{2}{*}{ G3 } & $r$ & $-.976 * *$ & $-.984 * *$ & $-.975 * *$ & $-.991 * *$ \\
\hline & $\begin{array}{l}p \\
\text { value }\end{array}$ & $<0.001$ & $<0.001$ & $<0.001$ & $<0.001$ \\
\hline \multirow[t]{2}{*}{ BG1 } & $r$ & 0.033 & -0.221 & -0.403 & $-.804 * *$ \\
\hline & $\begin{array}{l}p \\
\text { value }\end{array}$ & 0.923 & 0.515 & 0.219 & 0.003 \\
\hline \multirow[t]{2}{*}{ BG2 } & $r$ & $-.977 * *$ & $-.986 * *$ & $-.984 * *$ & $-.978 * *$ \\
\hline & $\begin{array}{l}p \\
\text { value }\end{array}$ & $<0.001$ & $<0.001$ & $<0.001$ & $<0.001$ \\
\hline \multirow[t]{2}{*}{ BG3 } & $r$ & $-.990 * *$ & $-.995 * *$ & $-.991 * *$ & $-.984 * *$ \\
\hline & $\begin{array}{l}p \\
\text { value }\end{array}$ & $<0.001$ & $<0.001$ & $<0.001$ & $<0.001$ \\
\hline
\end{tabular}




\begin{tabular}{|c|c|c|c|c|c|}
\hline \multirow[t]{2}{*}{ B1 } & $r$ & $.983 * *$ & $.982 * *$ & $.981 * *$ & $.978 * *$ \\
\hline & $\begin{array}{l}p \\
\text { value }\end{array}$ & $<0.001$ & $<0.001$ & $<0.001$ & $<0.001$ \\
\hline \multirow[t]{2}{*}{ B2 } & $r$ & $-.922 * *$ & $-.966 * *$ & $-.956^{* *}$ & $-.950 * *$ \\
\hline & $\begin{array}{l}p \\
\text { value }\end{array}$ & $<0.001$ & $<0.001$ & $<0.001$ & $<0.001$ \\
\hline \multirow[t]{2}{*}{ B3 } & $r$ & $-.980 * *$ & $-.979 * *$ & $-.987 * *$ & $-.980 * *$ \\
\hline & $\begin{array}{l}p \\
\text { value }\end{array}$ & $<0.001$ & $<0.001$ & $<0.001$ & $<0.001$ \\
\hline \multirow[t]{2}{*}{ BV1 } & $r$ & $.960 * *$ & $.830 * *$ & $.956 * *$ & $.910 * *$ \\
\hline & $\begin{array}{l}p \\
\text { value }\end{array}$ & $<0.001$ & 0.002 & $<0.001$ & $<0.001$ \\
\hline \multirow[t]{2}{*}{ BV2 } & $r$ & $-.973 * *$ & $-.980 * *$ & $-.966^{* *}$ & $-.948 * *$ \\
\hline & $\begin{array}{l}p \\
\text { value }\end{array}$ & $<0.001$ & $<0.001$ & $<0.001$ & $<0.001$ \\
\hline \multirow[t]{2}{*}{ BV3 } & $r$ & $-.978 * *$ & $-.955 * *$ & $-.899 * *$ & $-.846 * *$ \\
\hline & $\begin{array}{l}p \\
\text { value } \\
\end{array}$ & $<0.001$ & $<0.001$ & $<0.001$ & 0.001 \\
\hline \multirow[t]{2}{*}{ V1 } & $r$ & $.958 * *$ & $.972 * *$ & $.985 * *$ & $.960 * *$ \\
\hline & $\begin{array}{l}p \\
\text { value }\end{array}$ & $<0.001$ & $<0.001$ & $<0.001$ & $<0.001$ \\
\hline \multirow[t]{2}{*}{ V2 } & $r$ & $.972 * *$ & $.984 * *$ & $.983 * *$ & $.984 * *$ \\
\hline & $\begin{array}{l}p \\
\text { value }\end{array}$ & $<0.001$ & $<0.001$ & $<0.001$ & $<0.001$ \\
\hline \multirow[t]{2}{*}{ V3 } & $r$ & $.968 * *$ & $.987 * *$ & $.985 * *$ & $.958 * *$ \\
\hline & $\begin{array}{l}p \\
\text { value }\end{array}$ & $<0.001$ & $<0.001$ & $<0.001$ & $<0.001$ \\
\hline
\end{tabular}

** Correlation is significant at the 0.01 level (2-tailed).

* Correlation is significant at the 0.05 level (2-tailed).

51 Journal of Design and Built Environment Vol. 17 (1), June 2017 Amin G. et. al 



Figure 9. Average of dependent variables trend line for each colour on time spending

Table 9. Correlation coefficient $(r)$ of all colours on each dependent variable, sorted from lower to higher value

\begin{tabular}{|c|c|c|c|c|c|c|c|}
\hline \multicolumn{2}{|c|}{$\begin{array}{c}\text { Blood pressure } \\
\text { (systolic) }\end{array}$} & \multicolumn{2}{c|}{$\begin{array}{c}\text { Blood pressure } \\
\text { (diastolic) }\end{array}$} & \multicolumn{2}{c|}{ Heart beat rate } & \multicolumn{2}{c|}{$\begin{array}{c}\text { Skin } \\
\text { temperature }\end{array}$} \\
\hline BG3 & -0.99 & BG3 & -0.995 & BG3 & -0.991 & G3 & $\begin{array}{c}- \\
0.991\end{array}$ \\
\hline B3 & -0.98 & BG2 & -0.986 & B3 & -0.987 & BG3 & - \\
\hline
\end{tabular}

52 Journal of Design and Built Environment Vol. 17 (1), June 2017 Amin G. et. al 


\begin{tabular}{|c|c|c|c|c|c|c|c|}
\hline & & & & & & & 0.984 \\
\hline BV3 & -0.978 & G3 & -0.984 & G2 & -0.986 & B3 & -0.98 \\
\hline BG2 & -0.977 & BV2 & -0.98 & BG2 & -0.984 & BG2 & $\begin{array}{c}- \\
0.978\end{array}$ \\
\hline G3 & -0.976 & B3 & -0.979 & G3 & -0.975 & G2 & $\begin{array}{c}- \\
0.961\end{array}$ \\
\hline G1 & -0.974 & G1 & -0.971 & BV2 & -0.966 & B2 & -0.95 \\
\hline BV2 & -0.973 & B2 & -0.966 & B2 & -0.956 & BV2 & - \\
\hline G2 & -0.969 & BV3 & -0.955 & G1 & -0.944 & G1 & - \\
\hline B2 & -0.922 & G2 & -0.942 & BV3 & -0.899 & BV3 & 0.846 \\
\hline BG1 & 0.033 & BG1 & -0.221 & BG1 & -0.403 & BG1 & - \\
\hline V1 & 0.958 & BV1 & 0.83 & BV1 & 0.956 & BV1 & 0.91 \\
\hline BV1 & 0.96 & V1 & 0.972 & B1 & 0.981 & V3 & 0.958 \\
\hline V3 & 0.968 & B1 & 0.982 & V2 & 0.983 & V1 & 0.96 \\
\hline V2 & 0.972 & V2 & 0.984 & V1 & 0.985 & B1 & 0.978 \\
\hline B1 & 0.983 & V3 & 0.987 & V3 & 0.985 & V2 & 0.984 \\
\hline
\end{tabular}

Findings revealed that BG3 and G3 embraced the strongest (negative) relationships with the dependent variables ( $p$-value $=-0.99)$. This indicates the lightest blue-green and the lightest green have the highest correlation with the relaxation of elderly occupants through significantly decreasing the maximum blood pressure (systolic), minimum blood pressure (diastolic), and heart beat rate (beats/min). In contrary, B1, V3, and V2 encompassed the strongest (positive) relationships with the dependent variables (p-value $=0.983 \sim$ 0.987) demonstrating that the darkest blue and the two lightest violets have the lowest correlation with the relaxation of elderly occupants via increasing the dependent variables.

The analysis illustrated that in general, green (G) color has the most negative correlation with all dependent variables. In particular, green color has a strong relationship with blood pressure systolic $(\mathrm{r}=$ $-0.719)$, blood pressure diastolic $(\mathrm{r}=-0.760)$ as well as heart beat rate $(\mathrm{r}=-0.669)$, while it has a moderate relationship with skin temperature $(\mathrm{r}=-0.435)$. The result showed that blue-green 3 (BG3) and green 3 (G3) had the most positive impact on three dependent variables as a result of negative direction, BG3 on blood pressure systolic ( $\mathrm{r}$ $=-0.99)$, blood pressure diastolic $(\mathrm{r}=$ $0.995)$, heart beat rate $(\mathrm{r}=-0.991)$ and $\mathrm{G} 3$ on skin temperature $(\mathrm{r}=-0.991)$. Furthermore, B1, V3, and V2 had the most negative impact following the correlation coefficient (r) values of dependent variables, as a result of having a strong relationship in a positive direction. The result also shows 
the lighter colour has a more positive impact on relaxation. However, the darker colour has, the less positive impact, which means in each color, intensity number 3 received a more positive impact, and intensity number 1 obtained a lower impact. Figure 10 graphically represents the p-value of each colour intensity on dependent variables.
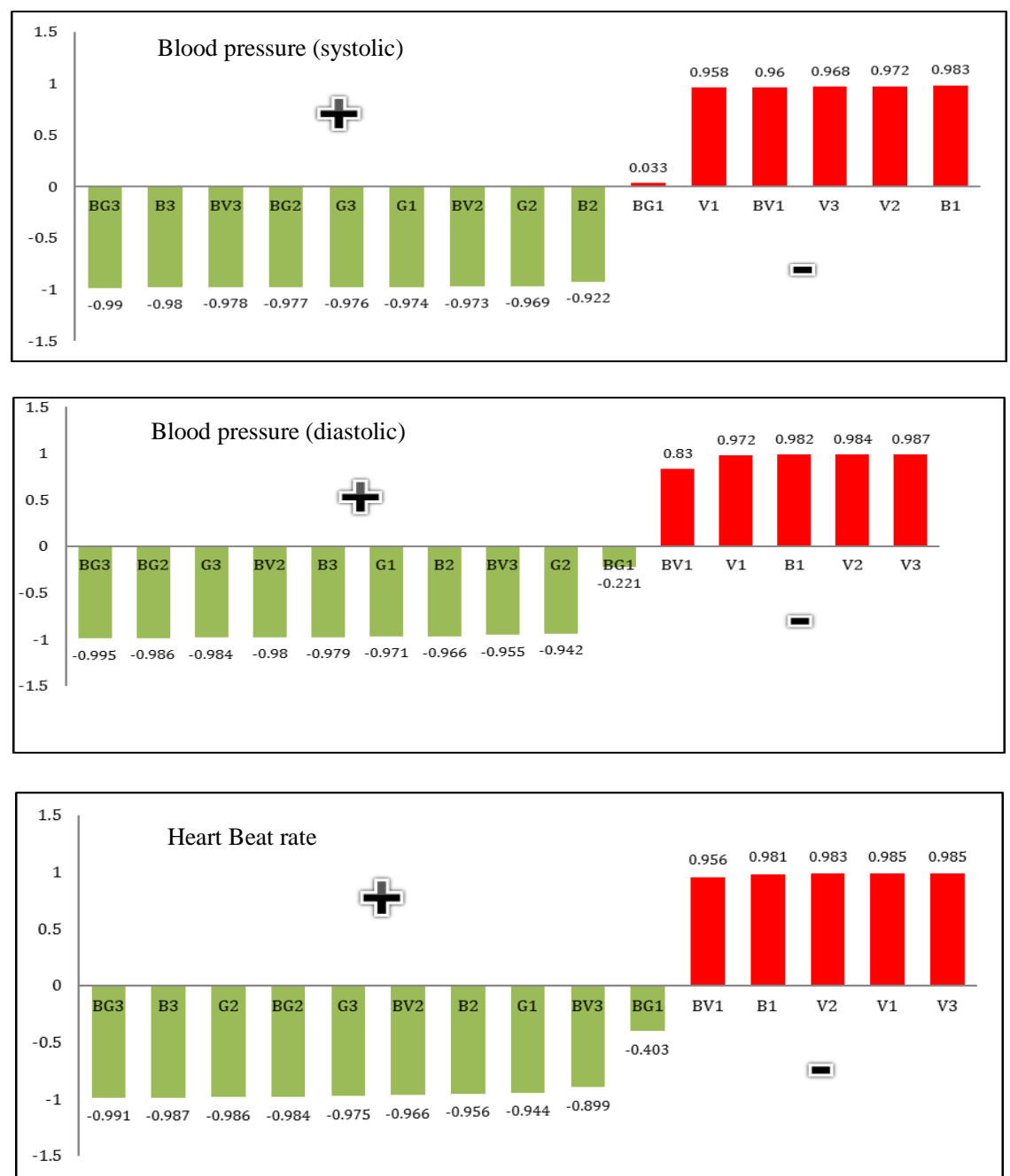

54 Journal of Design and Built Environment Vol. 17 (1), June 2017 Amin G. et. al 


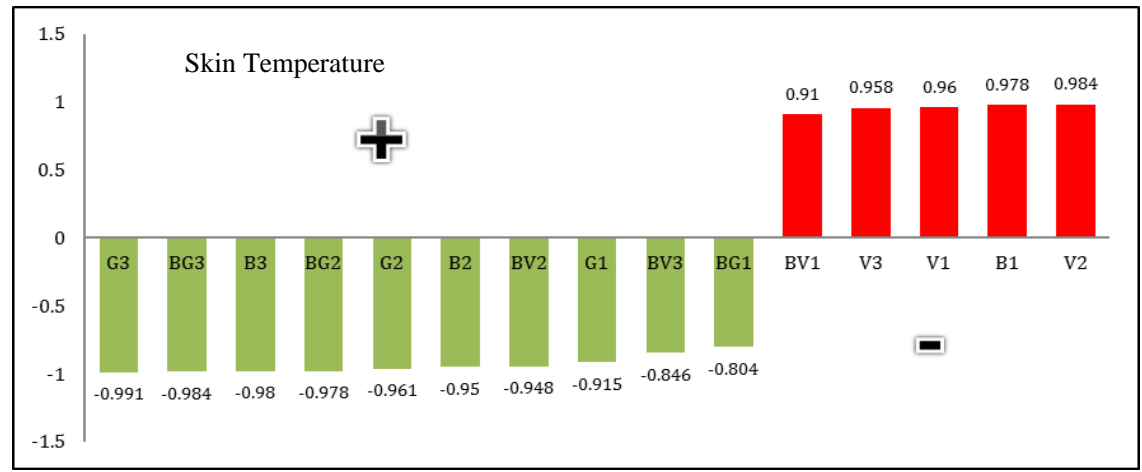

Figure 10: p-value of each colour intensity on dependent variables

The impact of color on elderly physiological parameters have strong correlation relationship with time spent (the time participants spent looking at each colour), which means by time spent; color has more impact on elderly. Two ways ANOVA test has identified the fastest impact color on participants. Figure 11 shows that all the colors start to affect dependent variables, mostly on third minute while blue-green 3 (BG3) starts to impact at the beginning of second minute. The trend line, which shows the average of colors impact on dependent variables has the downwards highest slope on BG3 and G3 in comparison with the other colors. It is undeniable to say that BG3 and G3 (lightest blue-green and lightest green color) has the most positive impact on elderly. Furthermore, BG3 has the fastest positive impact on dependent variables (See Figure 11). Finding also shows that the lighter intensities have more positive impact on dependent variables than the darker intensities 

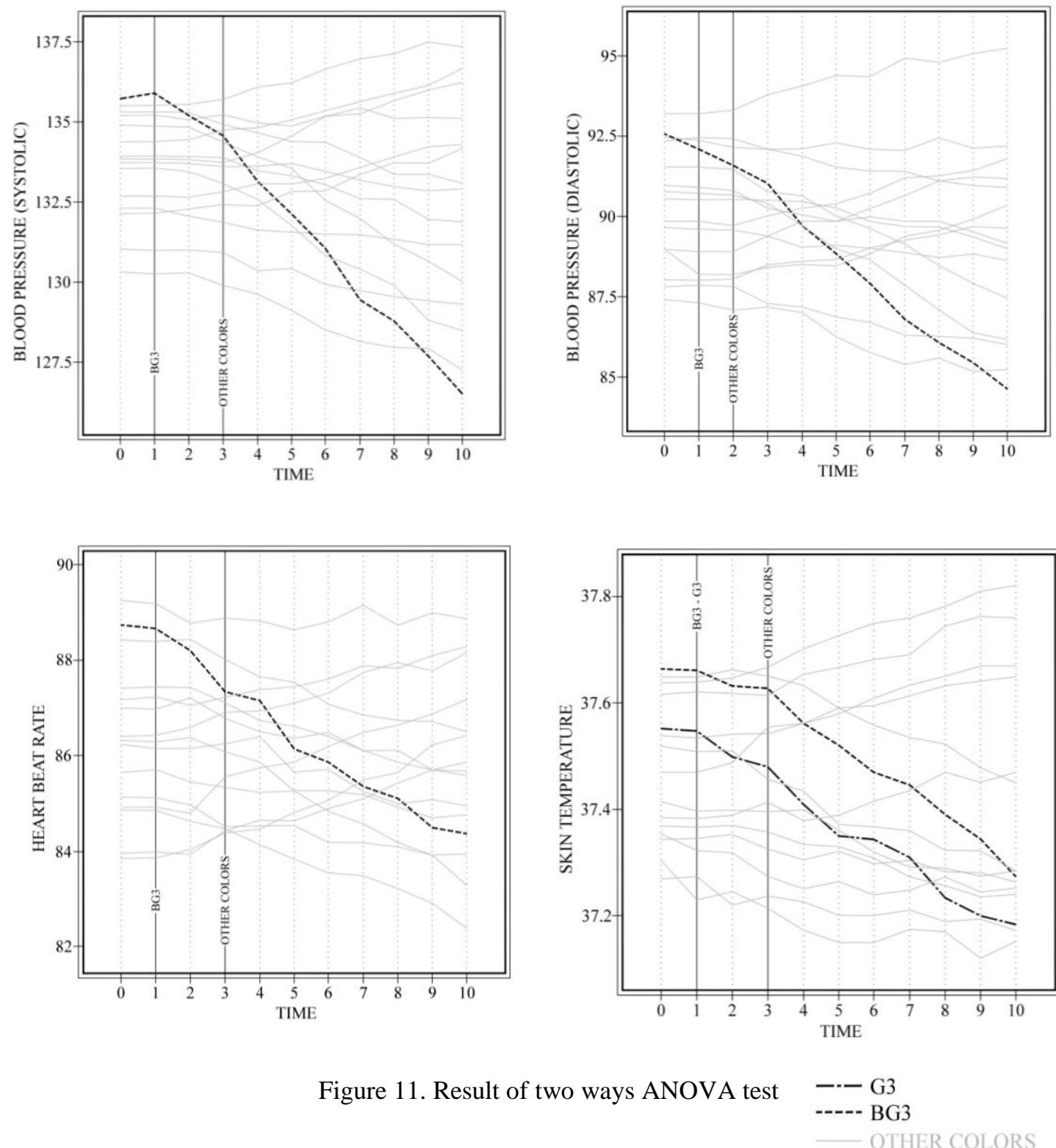

\subsection{DISCUSSIONS}

This study experimented the effect of cool colours on the elderly occupants of high-rise buildings in Kuala Lumpur to identify their most positive impact as environmental stimulus in common indoor facilities. Despite the fact that the result shows green color has more impact on elderly in comparison with other colors, the lightest spectrum in each colour have the most positive impact. Results of this study are in 
line with the findings of Knez (2001), Leather et al. (2003), Dijkstra (2006), and Elliot and Maier (2014) that proves that colour as environmental stimulus encompasses potentials to influence elderlies` mood and feeling. This study supports the previous studies, which were analyzed warm colors associated with aroused feeling and cool colors associated with calm and relaxation feeling (Kaya \& Epps, 2004; Elliot and Maier, 2014). However, violet and dark blue that were categorized under cool colors have not associated with calm and relaxation feeling.

Green and blue colors in most intensity have a positive impact on relaxation feeling while dark blue spectrum does not have any correlation with that feeling in comparison to the others with the dependent variables (p-value $=0.98)$. This supports findings by Dijkstra et al. (2006) that blue and green colours have the most positive impact, and that green colour offers less stress. The result of this study also has some parallels with Kaya and Epps`s work (2004). They also discovered that green color has a more positive impact. There is no doubt that green color associated with nature and greenery. As a result, people get influenced by the history of nature on their unconscious (Kaya and Epps. 2004), which support Wexner`s (1954) conclusion that green color has the most positive impact as environmental stimulus. This study also strongly supports results by Ulrich (1984), Wong (2001), Ross et al. (2013) and Tsunetsugu et al. (2013) that the visual impact of environmental stimulus effect blood pressure (systolic, diastolic), heart beat rate and skin temperature.

\section{CONCLUSION}

The study covers elderly residents above 60 years old of Kuala Lumpur high-rise condominium to test the effectiveness of cool colours in order to develop the general relaxation and recreational facilities, with more attention to the expectations of the elderlies. The elderlies limited to Malay, as Malaysian population is dominated by this race (Jabatan Perangkaan Malaysia, 2013). The case studies have limited to middleincome condominium as the majority of the existing condominiums are under this group (Ismail, 2014).

This study put forward that the majority of common indoor facilities of these condominiums in Kuala Lumpur are not entirely under the expectation of elderlies. Colour is one of the most effective environmental stimulus. While other studies have proven the positive impact of cool colours on human, this study identified the impact of each cool colour in fifteen intensities on Malay elderly residents of Kuala Lumpur high-rise condominiums. This study realized the lightest blue-green and the lightest green has the most positive impact on Malay elderlies. This study recognized that $\mathrm{B} 2$ had no significant impact on them, while $\mathrm{B} 1, \mathrm{~V} 3$, and V2 have an adverse impact on the participants. It is essential to choose the appropriate colours in accordance with the function of the indoor environment. Finally, the findings demonstrated that BG3 and G3 colours could have significant positive impact on the residents` quality of life and mental health on the long-term. It helps them to feel safe and satisfy from the environment when most of their issues come from mental diseases.

The study draws attention to the following concluding remarks:

- The majority of common indoor facilities of high-rise condominiums in Kuala Lumpur are not entirely by the expectation of elderlies;

- Regardless of the different intensities, in general, green color 
has more relaxation on Malay elderlies residents;

- Looking at the different intensities, the lowest blue-green and the lowest green have the most positive impact on Malay elderlies residents;

- B2 has no significant impact on Malay elderly;

- B1, V3, and V2 have negative impact on Malay elderly.

Each colour in different intensities impact elderlies differently. While, Visual impact of colour as environmental stimulus on any intensity can significantly measure through blood pressure, heart beat rate and skin temperature (Ross et al., 2013), measuring the effectiveness of other colour intensities such as warm colours recommended for future studies. There are other stimulus that could be effective in relaxing psychologically to increase the elderlies mental health, such as light, texture, and form. These aspects demand further studies as well. Marital status may affect the visual impact of color on elderly, which were not possible to test it in this study. Testing the effect of color on single or married elderly is recommended for future studies.

\section{ACKNOWLEDGEMENTS}

The authors would like to thank Dr. Danaee, a Research Fellow at Academic Development Centre, University of Malaya for his contribution to the statistical analysis of this project. Special thanks to the psychiatrists: Dr. Ezatollah Ghasemi and Dr. Mehr Pouya, particularly for their guidance in running the experimental phase of the study.

\section{REFERENCES}

Ainoriza Mohd Aini , Nooraisyilah Murni \&
Wan Nor Azriyati Wan Abd Aziz (2016). Housing Aspirations of the Elderly in Malaysia: A Comparison of Urban and Rural Areas. Journal of Design and Built Environment Vol. 16 (2), December 2016, 30-43.

Babin, B. J., Hardesty, D. M., \& Suter, T. A. (2003). Color and shopping intentions: The intervening effect of price fairness and perceived affect. Journal of Business Research, 56, 541-551.

Bailey, (2006). The real effect of warm-cool colors. WUCSE-20060-17, 63130, 314935-6160.

Barbara, M., (2011). Dynamics of international advertising: theoretical and practical perspectives. Peter Lang, Business \& economics, 105-144.

Birren, F. (1961). Color Psychology and Color Therapy: A Factual Study of the Influence of Color on Human Life. New Hyde Park, NY: University Books.

Blake, R., Rizzo, M., McEvoy, S., (2008), Aging and perception of visual form from temporal structure. Psychology and Aging, 23(1): 181-9.

Blažun, H., Vošner, J., Kokol, P., Saranto, K., \& Rissanen, S. (2014). Elderly people's interaction with advanced technology. Studies in Health Technology and Informatics, Volume 201, ISSN: 09269630 ISBN: 978161499414-5, 1-10.

Cooper, B. A., Ahrentzen, S., \& Hasselkus, B. R., (1991). Post-occupancy evaluation: an environment-behaviour technique for assessing the built environment. Canadian Journal of Occupational Therapy, 58(4), 181-188.

David, E., Watkins, (2011). Heating Services in Buildings. West Sussex, UK: John Wiley \& Sons Technology \& Engineering, 155-176.

Deanne, B., (2000). Influences of Color in Healthcare: Nature, Technology, and Culture. Herman Miller for healthcare, 
49464-0302, 8006280058.

Dijkstra, K., Pieterse, M., \& Pruyn, A, (2006). Physical environmental stimuli that turn healthcare facilities into healing environments through psychologically mediated effects: Systematic review. Journal of Advanced Nursing, 166-181.

Dittmar, M. (2001). Changing colour preferences with ageing: A comparative study on younger and older native germans aged 19-90 years. Gerontology, 47, 26-219.

Dong, J., Guo, Y.R., Jiang and L.Z., (2014). The public space design based on the living needs of the elderly. Applied Mechanics and Materials, Volume 584586, ISSN: 16609336, 796-800.

Dociu, M., Ratezanu, I., (2013). Urban space and urban modernization benefits. Quality - Access to Success, 103-104.

Elliot, A.J., Maier, M.A., (2014). Color psychology: Effects of perceiving color on psychological functioning in humans. Web of Science, Annual Review of Psychology, Volume 65, 95120.

Faul, F., Erdfelder, E., Lang, A.-G., \& Buchner, A. (2007). G*Power 3: A flexible statistical power analysis program for the social, behavioral, and biomedical sciences. Behavior Research Methods, 39, 175-191

Faul, F., Erdfelder, E., Buchner, A., \& Lang, A.-G. (2009). Statistical power analyses using $G^{*}$ Power 3.1: Tests for correlation and regression analyses. Behavior Research Methods, 41, 11491160

Feder, E., Feder, B. (1981). The Expressive Arts Therapies. Upper Saddle River, NJ: Prentice Hall.

Gabriel, M., Stirling, C., Faulkner, L. B., (2014). Future housing and support needs of people with dementia. AHURI Positioning Paper, Volume 159, ISSN:
18349250 ISBN: 978-192207553-6, 161.

Gifford, R., (1988). Light, decor, arousal, comfort, and communication. Journal of Environmental Psychology, 8, 177-189.

Globalsources, (2016), 8-in-1 8 functions infrared thermometer, [online], China, estne.manufacturer.globalsources.com,

Available from: http://estne.manufacturer.globalsources. com/si/6008843468599/pdtl/Earthermometer/1123730858/8-in-1-bodyinfrared-ear-thermometer.htm, [Accessed 28 January 2016].

Hatice, S. T., Emine, M. Y., Ipek, A., (2007). Evaluation of elderly people's requirements in public open spaces: A case study in Bornova District (Izmir, Turkey), Building and Environment, Volume 42, 2035-2045.

HelpAge India, (2011), Problems of the elderly, [online], India, helpageindiaprogramme.org, Available from:

http://www.helpageindiaprogramme.org /Elderly\%20Issues/problems_of_the_el derly/index.html, [Accessed 12 September 2014].

Hidayetoglu, M. L., Yildirim, K., Akalin, A., (2011). The effects of color and light on indoor wayfinding and the evaluation of the perceived environment. Journal of Environmental Psychology, 32, 50-58.

Heller, E., (2009), Psychologie de la couleur - Effets et symboliques. Pyramyd (French translation). ISBN 978-235017-156-2, 87-104.

Ho, G., Scialfa, C. T., Caird, J. K., Graw, T., (2001), Visual search for traffic signs: The effects of clutter, luminance, and aging. Human Factors, 43: 194-207

Huchendorf, L., (2007). The Effects of Color on Memory. W-L Journal of Undergraduate Research X, 1-4.

iHealth Lab, (2016), wireless blood pressure monitor, [online], US, ihealthlabs.com, 
Available

from:

https://ihealthlabs.com/blood-pressure-

monitors/wireless-blood-pressure-

monitor/ [Accessed 28 January 2016].

Ismail, E., (2014) Interviewed by Amin Ghashghaei. Kuala Lumpur city hall center: 21 June 2014.

Jabatan Perangkaan Malaysia, (2013). Preliminary count report. Population and housing census of Malaysia, Department of statistics, Malaysia

Jacob, K. W., \& Suess, J. F., (1975). Effects of four psychological primary colors on anxiety state. Perceptual and Motor Skills, 41, 207-210.

Jiang, F., Lu and S., (2014). Up or down? How culture and colour affect judgments. Journal of Behavioral Decision Making, 226-234.

Johnny, K. W. W., Martin, S., Laurie, B., Kai W., (2014). The effects of the indoor environment of residential care homes on dementia suffers in Hong Kong: A critical incident technique approach, Building and Environment, Volume 73, 32-39.

Kang, K. Y., \& Lee, K. H. (2009). Experiment of color schemes for the elderly in apartment bathrooms. Journal of Asian Architecture and Building Engineering, $\quad 8(1), \quad 103-110$. 10.3130/jaabe.8.103

Kaya, N., \& Epps, H., (2004). Relationship between color and emotion: A study of college students. College Student Journal, 38(3), 396-405.

Kazuyo, T., Ikue, M., Tomonori. S., Yoshika, K., (2015). Effects of seasonal illumination and thermal environments on sleep in elderly men, Building and Environment, Volume 88, 83-88.

Knez, I., (2001). Effects of color of light on nonvisual psychological processes. Journal of Environmental Psychology, 21, 201-208.

Kurt A. and Jellinger, (2014). Neuropathology of multiple system atrophy: New thoughts about pathogenesis. Movement Disorders, Volume 29, Issue 14, 1720-1741.

Leather, P., Beale, D., Santos, A., Watts, J., \& Lee, L., (2003). Outcomes of environmental appraisal of different hospital waiting areas. Environment and Behavior, 35, 842-869.

Li, C.F and Shi, H.T, (2014). Medical space oriented color psychology perception model, 4th International Conference on Civil Engineering, Architecture and Building Materials. Applied Mechanics and Materials, 587-589, 461-467.

Lim, K.H., Jasvindar, K., and Normala, I., (2014). Risk factors of home injury among elderly people in Malaysia. Asian Journal of Gerontology and Geriatrics, 16-20.

Iliffe, S. and Manthorpe, J., (2014). A new settlement for health and social care? BMJ Publishing Group, SSN: 17561833

Lord, S. R., (2006). Visual risk factors for falls in older people. Age and Ageing, 35(Supplement 2): ii42-5

Lyle, F. Bachman, (2004). Statistical Analyses for Language Assessment. UK: Cambridge University Press, 55100.

Mattila, A., Wirtz, J., (2001a). Congruency of scent and music as a driver of instore evaluations and behavior. Journal of Retailing, 77, 89, 273-289.

Mehrabian, A., (1994). Manual for the revised trait arousability (converse of the stimulus screening) scale. Alta Mesa Road, USA 93940.

Myers, D. G., (2006). Psychology. (8th ed.). New York: Worth. O'Connell, B. J., Harper, R. S., \& McAndrew, F. T. (1985). Grip strength as a function of exposure to red or green visual stimulation. Perceptual and Motor Skills, 61, 1157-1158.

Naseri. G. H., Tamizi. M., (2011). Assessing the Function of Light and Color in 
Architectural View. World Academy of Science, Engineering and Technology, 268-270.

Noonan, J.E., Nguyen, T.T., (2013). Retinal arteriolar dilation to flicker light is reduced on short-term retesting. Investigative Ophthalmology and Visual Science, 7764-7768.

Ogundele, A.O., (2010). Comparative assessment of residents' satisfaction with condominiums: Case studies from Kuala Lumpur metropolis. Hong Kong; China; 2 June 2010; Code 100509: Conference on Infrastructure and Environment, IPCIE 2010.

Randstad Workmonitor, (2015), Three quarters of Malaysia employees expect to work longer than the current retirement age: Randstad Workmonitor, [online], Malaysia, randstad.com.my, Available from: http://www.randstad.com.my/workforce 360/articles/three-quarters-of-malaysiaemployees-expect-to-work-longer-thanthe-current-retirement-age-randstadworkmonitor, [Accessed 19 January 2015].

Ross, M.J., Guthrie, P., and Dumont, J.C., (2013). The impact of modulated, colored light on the autonomic nervous system. Advances in mind-body medicine, Volume 27, Issue 4, 7-16.

Rovai, A., Baker, J.D., Ponton, M.K., (2013). Social science research design and statistics. Chesapeake, VA: Watertee Press.

Schweitzer, M., Gilpin, L., \& Frampton, S., (2004). Healing spaces: Elements of environmental design that make an impact on health. The Journal of Alternative and Complementary Medicine, 10, 71-83.

Shariful, S., Monjur, M., \& Andrew, P., L., Kagawa, T., and Miyazaki, Y., (2013). Physiological and psychological effects of viewing urban forest landscapes assessed by multiple measurements.
(2012). Therapeutic lighting design for the elderly: a review. Perspectives in Public Health, ISSN 1757-9139 DOI: $10.1177 / 1757913911422288$

Sturnieks, D. L., George, R., Lord, S. R., (2008), Balance disorders in the elderly. Clinical Neurophysiology, 38: 467-78

Sloan, D. A., \& Arneill, A. B., (2003). Healthcare environments and patient outcomes. A review of the literature, Environment and Behavior, 35, 665694.

Stamps, A. E., Jr, (1990). Use of photographs to simulate environments: A meta-analysis. Perceptual and Motor Skills, 71, 907-913.

Stella, R. Q., (2015). Routledge Handbook of Families in Asia, London and New York: Routledge taylor and francis group, 380-510.

Tate, F.B., Allen, H. (1985). Color preferences and the aged individual: Implications for art therapy. The Arts in Psychotherapy, 12, 9-165.

Temelová, J., (2014). The changing environment and neighbourhood satisfaction in socialist high-rise panel housing estates: The time-comparative perceptions of elderly residents in Prague. Elsevier B.V., 82-91.

Thompson, C., (2011). Natural environments and their impact on activity, health and quality of life. Applied Psychology: Health and WellBeing, 3, 230-260.

Tofle, R. B., Schwartz, B., Yoon, S., \& Max, R. A., (2004). Color in healthcare environments: A critical review of the research literature. California: The Coalition for Health Environments Research (CHER).

Tsunetsugu, Y., Lee, J., Park, B., Tyrväinen. Landscape and Urban Planning, Volume 113, 90-93.

Ulrich, R. S., (1984). View through the window may influence recovery from 
surgery. American association for the advancement of science, volume 224, issue 4647, 112-184.

Ulrich, R. S., (1995). Effects of healthcare interior design on wellness: Theory and recent scientific research. New York: Van Nostrand Reinhold, Innovations in healthcare design, 88-104.

Ulrich, R. S., Zimring, C., Quan, X., Joseph, A., \& Choudhary, R., (2004). The role of the physical environment in the hospital of the 21st century: A once-ina-lifetime opportunity. Martinez, CA: The Center for Health Design.

Veiel, L. L., Storandt, M., Abrams, R. A., (2006), Visual search for change in older adults. Psychology and Aging, 21: 754-62
Wexner, L. B., (1954). The degree to which colors (hues) are associated with moodtones. Journal of Applied Psychology, $38,432-435$.

Willard R.D., Jeffrey E. C., Steven J. G., (2008). Color in an optimum learning environment. International Center for Leadership in Education.

William, J. F., (2015). Review of some effects of climate change on indoor environmental quality and health and associated no-regrets mitigation measures, Building and Environment, Volume 86, 70-80.

Wong. J. W. S., (2001). The impact of viewing a garden on physiological health of elderly women. National Library of Canada, 0-612-61959-1. 